\title{
Guest editorial: Management of malignant lymphoma is continuously improving
}

\author{
Kensei Tobinai
}

Received: 3 October 2012/Revised: 18 October 2012/Accepted: 18 October 2012/Published online: 30 October 2012

(C) The Japanese Society of Hematology 2012

This issue of IJH contains four "Progress in Hematology $(\mathrm{PIH})$ " review articles describing the management of malignant lymphoma, with a focus on recent clinical trials. Malignant lymphoma, characterized by its marked heterogeneity, is the most frequent hematologic malignancy in the world. Among the various subtypes of malignant lymphoma, the following three are clinically important: Hodgkin lymphoma, follicular lymphoma (FL), and diffuse large B cell lymphoma (DLBCL). The current and future management of these three major subtypes are discussed by internationally distinguished lymphoma experts who have contributed to the establishment of the current standard management of each subtype. In addition, the current and future management of NK/T cell lymphoma is discussed by Dr. Yamaguchi, based on clinical trials recently published by her group.

Current issues to be addressed in the management of malignant lymphoma differ somewhat from disease to disease. In Hodgkin lymphoma, continuous efforts to establish more effective chemotherapy with or without radiotherapy have yielded high cure rates in patients with localized and advanced diseases. Drs. Eichenauer and Engert of the German Hodgkin Study Group (GHSG) prepared a comprehensive review article regarding the current standard management, based mainly on clinical trials conducted by GHSG. Treatment strategies for Hodgkin lymphoma are scientifically discussed, and updated information, including that on ongoing clinical trials, should help readers to better understand the most

\section{K. Tobinai $(\square)$}

Department of Hematology,

National Cancer Center Hospital,

Tokyo 104-0045, Japan

e-mail: ktobinai@ncc.go.jp successful history of using non-surgical treatment modalities in clinical oncology.

In FL, which remains incurable in most patients, the issues are somewhat different from those in Hodgkin lymphoma. Anti-CD20 monoclonal antibodies, such as rituximab, and radioimmunotherapy have markedly prolonged survival. In the second PIH article, Drs. Salles and Ghesquières of Groupe d'Etudes des Lymphomes de l'Adulte (GELA), which has recently been renamed the Lymphoma Study Association (LYSA), summarize recent advances in the management of patients with FL, based on the results of recent clinical trials including the PRIMA Study, which revealed the efficacy of maintenance use of rituximab [1]. Considering the marked heterogeneity of FL, the prolonged median survival time probably exceeding 15 years under the current treatment modalities, and the emergence of several less toxic but highly effective agents, personalized approaches will be more important in the treatment of FL in the future.

Since the establishment of rituximab plus $\mathrm{CHOP}$ as a standard therapy for DLBCL [2], progress has been less remarkable. In the third $\mathrm{PIH}$ article in this issue, Drs. Roschewski, Dunleavy, and Wilson of the National Cancer Institute in the United States present an excellent review of further progress in the treatment of DLBCL. An improved understanding of the biology of DLBCL has revealed a number of oncogenic driver mutations and signaling pathways essential for growth of the lymphoma cell. As many of these signaling pathways can be targeted by small molecule inhibitors, treatment of DLBCL may be in store for a paradigm shift.

Finally, Dr. Yamaguchi in Japan summarizes newly developed treatment strategies for NK/T cell lymphoma, based on the results of multicenter clinical trials. NK/T cell lymphoma is a distinct disease subtype with dismal prognosis 
when treated by conventional methods [3]. NK/T cell lymphoma is quite rare in Western countries, but relatively more common in East Asian countries, raising expectations that Asian investigators will contribute to the establishment of therapeutic advances. Recently, Dr. Yamaguchi and her colleagues published the results of prospective clinical trials of concurrent chemoradiotherapy for localized disease in the nasopharynx [4] and a novel combination chemotherapy regimen for advanced disease [5].

I am confident that all of the review articles in this issue of IJH will provide readers with the most up to date information on the current standard management for major subtypes of malignant lymphoma, and new insights into future directions in the management of the most frequent hematologic malignancy in the world.

\section{References}

1. Salles G, Seymour JF, Offner F, López-Guillermo A, Belada D, Xerri L, Feugier P, Bouabdallah R, Catalano JV, Brice P, Caballero D, Haioun C, Pedersen LM, Delmer A, Simpson D, Leppa S, Soubeyran P, Hagenbeek A, Casasnovas O, Intragumtornchai T, Fermé C, da Silva MG, Sebban C, Lister A, Estell JA,
Milone G, Sonet A, Mendila M, Coiffier B, Tilly H. Rituximab maintenance for 2 years in patients with high tumour burden follicular lymphoma responding to rituximab plus chemotherapy (PRIMA): a phase 3, randomised controlled trial. Lancet. 2011;377(9759):42-51.

2. Coiffier B, Lepage E, Briere J, Herbrecht R, Tilly H, Bouabdallah R, Morel P, Van Den Neste E, Salles G, Gaulard P, Reyes F, Lederlin P, Gisselbrecht C. CHOP chemotherapy plus rituximab compared with $\mathrm{CHOP}$ alone in elderly patients with diffuse largeB-cell lymphoma. N Engl J Med. 2002;346:235-42.

3. Vose J, Armitage J. International T-Cell Lymphoma Project. International peripheral T-cell and natural killer/T-cell lymphoma study: pathology findings and clinical outcomes. J Clin Oncol. 2008;26:4124-30.

4. Yamaguchi M, Tobinai K, Oguchi M, Ishizuka N, Kobayashi Y, Isobe $\mathrm{Y}$, Ishizawa $\mathrm{K}$, Maseki $\mathrm{N}$, Itoh $\mathrm{K}$, Usui $\mathrm{N}$, Wasada I, Kinoshita T, Ohshima K, Matsuno Y, Terauchi T, Nawano S, Ishikura S, Kagami Y, Hotta T, Oshimi K. Phase I/II study of concurrent chemoradiotherapy for localized nasal natural killer/Tcell lymphoma: Japan Clinical Oncology Group Study JCOG0211. J Clin Oncol. 2009;27:5594-600.

5. Yamaguchi M, Kwong YL, Kim WS, Maeda Y, Hashimoto C, Suh C, Izutsu K, Ishida F, Isobe Y, Sueoka E, Suzumiya J, Kodama T, Kimura H, Hyo R, Nakamura S, Oshimi K, Suzuki R. Phase II study of SMILE chemotherapy for newly diagnosed stage IV, relapsed, or refractory extranodal natural killer (NK)/T-cell lymphoma, nasal type: the NK-Cell Tumor Study Group study. J Clin Oncol. 2011;29:4410-6. 